\title{
Stabilitas Agregat Tanah, Populasi Jamur Pelarut P dan Hasil Jagung yang Dipengaruhi oleh Pupuk Hayati Mikroba Pelarut P dan Pupuk P pada Ultisols
}

\section{Betty Natalie Fitriatin1), Muhammad Agi Pratama'), dan Oviyanti Mulyani1)}

1) Staf Pengajar Fakultas Pertanian Universitas Padjadjaran

2) Alumni Program Studi Agroteknologi Fakultas Pertanian, Universitas Padjadjaran

Jl. Raya Bandung Sumedang Km 21 Jatinangor

Korespondensi: betty.natalie@unpad.ac.id

\begin{abstract}
Ultisols is a soil order with low available P. Phosphate Solubilizing Microbes is a group of microorganisms that has the ability to release $P$ for plants. The aim of this experiment was to determine effect of phosphate solubilizing microbes and P fertilizer on soil aggregate stability, PSF population and yield of maize (Zea mays L.) on Ultisols. This research was conducted from May 2016 to August 2016 at Ciparanje, Faculty of Agriculture, Universitas Padjadjaran. This research was arranged in Randomized Block Design (RBD), consisted of 9 treatments with 3 replications. The treatments were $100 \mathrm{~kg} \mathrm{ha}^{-1}$ of SP-36 fertilizer, $50 \mathrm{~kg} \mathrm{ha}^{-1}$ of biofertilizer, as well as combination of $S P-36$ fertilizer (50\% and 100\%) with the dose of biofertilizer (50\%, 100\% and 150\%). This experiment showed that the combination of biofertilizer and $P$ fertilizer gave significant effect on the population of PSF and yield of maize, but not for stability of soil aggregates. The application of SP-36 $50 \mathrm{~kg} \mathrm{ha}^{-1}$ and $50 \mathrm{~kg} \mathrm{ha}^{-1}$ PSM combination gave higher population of PSF and yield of maize.
\end{abstract}

Keywords: Biofertilizer, maize, phosphate- solubizing fungi, aggregate stability, Ultisols

\section{PENDAHULUAN}

Ultisols merupakan salah satu jenis tanah masam di Indonesia yang mempunyai sebaran luas mencapai 38,4 juta ha atau sekitar $29,7 \%$ dari 190 juta hektar luas daratan Indonesia (Masni dkk., 2015). Ultisols memiliki faktor pembatas seperti unsur hara makro yang rendah, bahan organik rendah serta aktivitas mikroba yang rendah dan dapat dijumpai pada berbagai relief (Prasetyo dan Suriadikarta, 2006).

Ultisols memiliki ciri-ciri $\mathrm{pH}$ dan $\mathrm{P}$ tersedia yang rendah, kandungan $\mathrm{Al}$ dan $\mathrm{Fe}$ tinggi serta agregat yang tidak mantap sehingga peka terhadap erosi. Tanah dengan agregat yang tidak mantap cenderung memiliki sifat fisik yang kurang baik bagi pertumbuhan tanaman, karena agregat tanah mempengaruhi porositas dan lamanya ketersediaan air pada tanah (Hardjowigeno, 2010).

Nilai pH yang masam, serta kandungan unsur hara $\mathrm{P}$ yang rendah akibat adanya fiksasi $\mathrm{P}$ merupakan kendala bagi pertumbuhan tanaman. Rendahnya $\mathrm{P}$ pada Ultisols disebabkan karena adanya unsur $\mathrm{Al}, \mathrm{Fe}$, dan Mn, yang dapat bereaksi masam serta Ca dan Mg yang bereaksi basa dalam tanah, sehingga menyebabkan $\mathrm{P}$ tidak tersedia bagi tanaman (Hardjowigeno, 2010). Fosfor (P) merupakan unsur yang diperlukan tanaman dalam jumlah yang besar (hara makro).

Upaya yang dapat dilakukan untuk meningkatkan produktivitas tanah Ultisol, salah satunya dengan pemupukan ke dalam tanah. Banyak macam pupuk yang dapat diberikan, salah satunya adalah pupuk anorganik. Pupuk anorganik memiliki efektivitas yang tinggi akan tetapi dalam proses produksinya, petani kerap kali mengalami kesulitan karena pupuk anorganik tidak tersedia secara langsung dari alam dan harganya relatif cukup mahal. Penggunaan pupuk anorganik yang terus menerus juga terbukti dapat menyebabkan kerusakan tanah dan pencemaran lingkungan (Parman, 2007). 
Salah satu teknologi yang dapat diterapkan dalam upaya menyeimbangkan suplai hara dan meningkatkan kesuburan tanah yaitu melalui aplikasi pupuk hayati. Oleh karena itu, pemanfaatan pupuk hayati seperti mikroba pelarut fosfat (MPF) yang terdiri dari bakteri dan jamur pelarut fosfat dapat dipergunakan untuk upaya mengatasi rendahnya P-tersedia tanah dan kebutuhan tanaman akan unsur hara $\mathrm{P}$ dapat terpenuhi (Fitriatin dkk., 2009).

Penggunaan pupuk MPF memiliki keunggulan seperti hemat energi, tidak mencemari lingkungan, mampu membantu meningkatkan kelarutan $\mathrm{P}$ yang terjerap, menghalangi terjerapnya $\mathrm{P}$ oleh unsur-unsur penjerap, dan mengurangi toksisitas $\mathrm{Al}^{3+}, \mathrm{Fe}^{3+}$, dan $\mathrm{Mn}^{2+}$ terhadap tanaman pada tanah masam (Elfiati dan Rauf, 2000). Hal ini terjadi karena mikroba tersebut mengeluarkan asamasam organik yang dapat membentuk kompleks stabil dengan kation-kation pengikat $P$ di dalam tanah sehingga dapat melarutkan $\mathrm{P}$ dari yang sebelumnya tidak tersedia bagi tanaman menjadi tersedia (Whitelaw, 2000 dalam Fitriatin, dkk., 2009). Unsur hara $P$ dengan pemberian pupuk anorganik dan pupuk hayati lebih cocok diberikan untuk tanaman semusim seperti jagung (Kasno, dkk., 2006).

Jagung (Zea mays L.) merupakan salah satu tanaman pangan pokok dunia khususnya Indonesia selain gandum dan padi. Permintaan akan komoditas jagung di Indonesia terus meningkat setiap tahunnya. Hal ini disebabkan karena beragamnya pemanfaatan jagung, seperti pangan, pakan ternak dan sektor industri yang telah mencapai 50\% kebutuhan nasional.

Permintaan jagung yang tinggi belum tentu diikuti dengan produksi yang tinggi pula. Rendahnya produktivitas salah satunya disebabkan karena unsur hara yang dibutuhkan tanaman belum tercukupi. Menurut hasil penelitian, jagung di Indonesia dapat menghasilkan 10-11 t/ha, namun produktivitas di lahan petani yang beragam membuat hasil rata-ratanya berkisar antara 3,2-8 t/ha (Sutoro, 2015). Upaya penyediaan unsur hara salah satunya dengan menggunakan pupuk hayati.

Peranan pupuk anorganik nyatanya tidak sepenuhnya dapat digantikan oleh pupuk hayati, sehingga alternatif terbaik adalah dengan menggunakan kombinasi pupuk hayati dengan pupuk anorganik (Elfiati dan Rauf, 2000). Aplikasi kombinasi pupuk hayati dengan pupuk anorganik penting dilakukan untuk meminimalisir dampak terhadap lingkungan akibat penggunaan pupuk anorganik yang berlebihan.

Berdasarkan uraian di atas, maka kajian mengenai pupuk $\mathrm{P}$ dan pupuk hayati mikroba pelarut fosfat terhadap populasi jamur pelarut fosfat, stabilitas agregat tanah dan hasil tanaman jagung pada Ultisols Jatinangor menjadi suatu kajian yang menarik untuk dilakukan.

\section{BAHAN DAN METODE}

\subsection{Waktu dan Tempat Penelitian}

Penelitian dilakukan dari bulan Mei 2016 hingga bulan Agustus 2016. Penelitian dilakukan di Kebun Percobaan Ciparanje, Fakultas Pertanian Universitas Padjadjaran yang berada pada ketinggian tempat $752 \mathrm{~m}$ di atas permukaan laut. Analisis MPF tanah awal, populasi JPF dan pembuatan pupuk hayati dilakukan di Laboratorium Mikrobiologi Tanah Fakultas Pertanian Universitas Padjadjaran, analisis kimia tanah dilakukan di Laboratorium Kesuburan Tanah dan Nutrisi Tanaman Departemen Ilmu Tanah dan Sumberdaya Lahan Fakultas Pertanian Universitas Padjadjaran. Analisis stabilitas agregat tanah dilakukan di Laboratorium Fisika Tanah Fakultas Pertanian Universitas Padjadjaran.

\subsection{Bahan dan Alat Penelitian}

Bahan yang digunakan dalam penelitian ini adalah: 
- Ultisols asal Jatinangor,

- Benih jagung varietas Pertiwi-2

- MPF Pseudomonas cepaceae, P. mallei, Aspergillus niger dan Penicillium sp. koleksi Laboratorium Mikrobiologi Tanah Unpad.

- Pupuk dasar berupa SP-36, Urea, KCl, dan pupuk kandang.

- Bahan pembawa MPF padat berupa kompos dan gambut saprik dengan perbandingan 1:1,

- Media Pikovskaya, $\mathrm{NaCl}$ fisiologis 0,85\%, $\mathrm{HCl} 25 \%$, pereaksi fosfat pekat, pereaksi pewarna $\mathrm{P}$.

Peralatan yang digunakan adalah spektrofotometer UV-VIS, alat sentrifius, Colony Counter, neraca analitik, tabung reaksi, Erlenmeyer, botol kocok, pipet mikro, gelas kimia, cawan petri, pembakar spirtus, autoclave, inkubator, ember, sekop, timbangan, embrat, alat tulis, alat dokumentasi dan program SPSS 21.

\subsection{Rancangan Percobaan}

Penelitian dilakukan dengan menggunakan Rancangan Acak Kelompok (RAK). Penelitian ini terdiri dari dari 9 perlakuan dan 3 ulangan. Perlakuan yang diberikan adalah sebagai berikut:

$$
\begin{array}{ll}
\mathrm{A} & : \text { Kontrol } \\
\mathrm{B} & : 100 \% \text { pupuk } \mathrm{P}\left(100 \mathrm{~kg} \mathrm{ha}^{-1}\right) \\
\mathrm{C} & : 100 \% \mathrm{MPF}\left(50 \mathrm{~kg} \mathrm{ha}^{-1}\right) \\
\mathrm{D} & : 50 \% \text { pupuk } \mathrm{P}+50 \% \mathrm{MPF} \\
\mathrm{E} & : 50 \% \text { pupuk } \mathrm{P}+100 \% \mathrm{MPF} \\
\mathrm{F} & : 50 \% \text { pupuk } \mathrm{P}+150 \% \mathrm{MPF} \\
\mathrm{G} & : 100 \% \text { pupuk } \mathrm{P}+50 \% \mathrm{MPF} \\
\mathrm{H} & : 100 \% \text { pupuk } \mathrm{P}+100 \% \mathrm{MPF} \\
\mathrm{I} & : 100 \% \text { pupuk } \mathrm{P}+150 \% \mathrm{MPF}
\end{array}
$$

Dosis SP-36 (100 \% rekomendasi: 100 $\mathrm{kg} / \mathrm{ha}$ ) setara dengan 1,76 g/tanaman sedangkan dosis Pupuk Hayati Fosfat (100 \% rekomendasi: $50 \mathrm{~kg} / \mathrm{ha}$ ) setara dengan 0,88 g/tanaman.

\subsection{Pengamatan dan Analisis Data}

Pengamatan yang dilakukan meliputi:

- Populasi JPF pada saat vegetatif akhir dengan metode Total Plate Count.

- Analisis stabilitas agregat tanah dengan menggunakan metode Loveday (1974).

- Komponen hasil jagung (bobot pipilan kering).

Data diuji menggunakan program Statistical Product and Service Solution (SPSS) 21. Sebelum dilakukan uji beda nyata, terlebih dahulu dilakukan uji normalitas (Kosmogorov-Smirnov). Pengujian terhadap pengaruh perlakuan dilakukan dengan menggunakan Analisis Varians pada taraf nyata 5\%. Apabila terdapat pengaruh nyata maka dilanjutkan dengan uji lanjut Least Significance Difference (LSD) pada taraf nyata 5\%.

\subsection{Pelaksanaan Penelitian}

\subsubsection{Perbanyakan Inokulan MPF}

Perbanyakan bakteri dilakukan pada media cair. Tahapan awal yaitu dengan mengambil satu ose kultur murni dari plat agar miring, lalu dipindahkan ke plat agar miring lainnya dan dilakukan inkubasi selama 24 jam. Isolat BPF yang sudah diinkubasikan ditambah $10 \mathrm{~mL} \mathrm{NaCl}$ fisiologis 0,85\% kemudian masing-masing dipindahtanamkan ke erlenmeyer yang berisi $190 \mathrm{~mL}$ media Nutrient Broth. Suspensi BPF dikocok menggunakan shaker dengan kecepatan 112 rpm pada suhu kamar selama 24 jam.

Perbanyakan jamur pelarut fosfat dilakukan pada media padat Potato Dextrose Agar (PDA). Jamur ditumbuhkan pada media PDA sampai memenuhi permukaan PDA kemudian ditambahkan $100 \mathrm{~mL} \quad \mathrm{NaCl}$ fisiologis 0,85\%. Keempat MPF ini kemudian digabungkan ke dalam erlenmeyer dan dikocok selama 10 menit yang selanjutnya diaplikasikan pada bahan pembawa padat gambut dan kompos dengan perbandingan $1: 1$. 


\subsubsection{Pembuatan Pupuk Hayati MPF}

Bahan pembawa terlebih dahulu disterilisasi menggunakan autoclave sebelum diinokulasikan suspensi MPF. Suspensi MPF yang diinokulasikan ke dalam bahan pembawa padat kompos dan gambut steril dengan perbandingan 1:1, kehalusan bahan lolos saringan 100 mesh atau $149 \mu \mathrm{m}$ dan kadar air 45\% (Simanungkalit dkk., 2006). Bakteri pelarut fosfat dan jamur pelarut fosfat dihitung terlebih dahulu populasinya dengan metode Total Plate Count sebelum dimasukkan ke dalam bahan pembawa.

Jumlah populasi BPF Pseudomonas mallei yang dimasukkan ke dalam bahan pembawa sebesar $2,3 \times 10^{8} \mathrm{CFU} / \mathrm{mL}$ dan $P$. cepaceae sebesar 2,7 $\quad$ x $10^{8} \quad \mathrm{CFU} / \mathrm{mL}$, sedangkan populasi JPF Aspergillus niger yang dimasukkan dalam bahan pembawa adalah $47,9 \times 10^{3} \mathrm{CFU} / \mathrm{mL}$ dan Penicillium sp sebesar $37,08 \times 10^{3} \mathrm{CFU} / \mathrm{mL}$. MPF yang diinokulasikan ke dalam bahan pembawa sebanyak 10\% volume berat bahan pembawanya $(10 \mathrm{~mL}$ dalam 100 g). Bahan pembawa yang sudah diinokulasikan MPF lalu diinkubasikan selama tiga hari.

\subsubsection{Pemupukan}

Aplikasi pupuk hayati di lapangan dilakukan dengan cara mencampurkan pupuk kandang dan MPF yang diaplikasikan dua hari sebelum penanaman jagung dilakukan. Dosis pupuk kandang sapi sebanyak 2 ton ha-1 (35,29 g/tanaman) dan dosis MPF dilakukan sesuai perlakuan, diaplikasikan ke dalam lubang tanam. Aplikasi perlakuan pupuk anorganik Urea, SP-36 dan KCl dilakukan pada saat umur tanaman 1 MST. Khusus untuk Urea, diaplikasikan secara bertahap 1, 4 dan 6 MST. Aplikasi pupuk anorganik dilakukan dengan cara menugal di samping tanaman dengan jarak 7 - $10 \mathrm{~cm}$ kemudian ditutup kembali dengan tanah. Dosis Urea yang diberikan $300 \mathrm{~kg} \mathrm{ha}^{-1}, \mathrm{KCl} 100 \mathrm{~kg} \mathrm{ha}^{-1}$ dan SP36 sesuai dengan perlakukan yang telah ditentukan.

\subsubsection{Pengambilan Contoh Tanah}

Contoh tanah untuk analisis stabilitas agregat tanah dan populasi JPF diambil pada fase vegetatif akhir yang dicirikan dengan munculnya bunga jantan tepatnya pada umur 8 MST. Pengambilan contoh dilakukan dengan cara mengambil tanah pada bagian baris tengah tanaman. Analisis stabilitas agregat tanah dilakukan pada masing-masing plot sebanyak 1 sampel dengan menggunakan ring sampler kemudian dilakukan analisis di laboratorium.

Contoh untuk analisis total populasi JPF dilakukan dengan mengambil contoh tanah segar sebanyak $50 \mathrm{~g}$ dari daerah perakaran tanaman lalu dilakukan penghitungan populasi JPF di laboratorium.

\subsubsection{Panen}

Panen dilakukan pada saat tanaman telah mencapai umur panen, yaitu pada umur 90 101 hari. Pemanenan dilakukan satu kali yaitu pada saat klobot sudah berwarna coklat, rambut berwarna hitam dan kering, populasi klobot kering 95\%, biji jagung bila ditekan dengan kuku tidak membekas. Jagung dipanen dengan menggunakan tangan kemudian dipipil, hasil dinyatakan dalam berat pipilan kering/plot perlakuan $\left(6 \mathrm{~m}^{2}\right)$.

\section{HASIL DAN PEMBAHASAN}

\subsection{Populasi Jamur Pelarut Fosfat}

Hasil uji statistik menunjukkan adanya pengaruh nyata dari pemberian perlakuan terhadap peningkatan populasi JPF tanah. Populasi JPF di rizosfer jagung dapat ditingkatkan dengan pemberian kombinasi perlakuan pupuk $\mathrm{P}$ dan MPF. Pemberian $100 \%$ pupuk SP-36 + 100\% MPF dapat meningkatkan populasi JPF di rizosfer jagung menjadi $18,33 \times 10^{4} \mathrm{CFU} \mathrm{g}^{-1}$ yang merupakan populasi JPF tertinggi. Namun jika dilihat dari efisiensi input ke dalam tanah, perlakuan 50\% pupuk SP-36 + 100\% MPF merupakan perlakuan yang dapat berpotensi lebih baik 
karena input yang lebih sedikit dapat menghasilkan pengaruh yang sama dengan total populasi $17,5 \times 10^{4} \mathrm{CFU} \mathrm{g}^{-1}$ terbukti berbeda nyata dengan kontrol.

Tingginya populasi JPF tanah pada perlakuan tersebut dikarenakan MPF membutuhkan adanya fosfat dalam bentuk tersedia dalam tanah untuk memenuhi kebutuhan dalam pertumbuhannya. Pemupukan $\mathrm{P}$ yang terus-menerus dan berlebih selama ini telah mengakibatkan terjadinya akumulasi residu $\mathrm{P}$ yang tinggi serta tidak diikuti dengan peningkatan hasil dan efisiensinya sangat rendah (Sitorus, 2013).

Tabel 1 Pengaruh kombinasi pupuk $\mathrm{P}$ dan MPF terhadap Pppulasi JPF pada Ultisols Jatinangor

\begin{tabular}{cc}
\hline Perlakuan & $\begin{array}{c}\text { Populasi BPF } \\
\left(10^{11} \mathrm{CFU} \mathrm{g}^{-1}\right)\end{array}$ \\
\hline A & 2,50 \\
B & 5,83 \\
C & 6,67 \\
D & $9,17^{*}$ \\
E & $17,50^{*}$ \\
F & 6,67 \\
G & 12,50 \\
H & $18,33^{*}$ \\
I & 11,67 \\
\hline Keterangan: Nilai rata-rata yang ditandai dengan \\
\multicolumn{2}{c}{ tanda * berbeda nyata dengan kontrol } \\
& menurut Uji Beda Nyata Terkecil (LSD) \\
& pada taraf nyata 5\%.
\end{tabular}

Peningkatan yang terjadi pada perlakuan $50 \%$ pupuk $\mathrm{P}+100 \%$ MPF dikarenakan MPF membutuhkan unsur hara seperti adanya fosfat sebagai sumber energi untuk berkembang dan melakukan metabolisme. Pupuk $\mathrm{P}$ merupakan salah satu sumber $\mathrm{P}$ dalam tanah untuk terjadinya proliferasi JPF, selain itu pupuk SP36 juga memiliki impurity seperti logam esensial sehingga pada penelitian ini, penggunaan kombinasi pupuk SP36 meningkatkan populasi JPF.

Persentasi populasi JPF yang tinggi dalam tanah diduga akan meningkatkan ketersediaan unsur $\mathrm{P}$ yang tersedia bagi tanaman. Hal ini sesuai dengan pernyataan Suliasih dkk., (2010) bahwa JPF dapat melarutkan fosfat terikat dalam tanah sehingga tersedia bagi tanaman. Aplikasi pupuk hayati yang dicoba pada penelitian ini memberikan efek yang positif terhadap populasi jamur pelarut fosfat yang nyata lebih tinggi dibandingkan perlakuan tanpa pupuk hayati yaitu perlakuan kontrol.

Kenyataan ini menunjukkan bahwa pupuk hayati ternyata dapat dimanfaatkan sebagai sumber bahan organik dan anorganik dalam tanah untuk memenuhi kebutuhan nutrisi jamur di dalam tanah. Hal ini dapat terjadi akibat adanya bahan aktif dari pupuk hayati yang sifat volatilitasnya lebih rendah dan lebih nonpolar sehingga lebih sulit terabsorpsi akar tumbuhan dan lebih banyak terurai di daerah rizosfer (Hardjowigeno, 2010).

\subsection{Stabilitas Agregat Tanah}

Berdasarkan hasil analisis ragam, perlakuan yang diberikan tidak berpengaruh nyata terhadap stabilitas agregat tanah. Hal ini diduga karena pengolahan tanah yang intensif akan berdampak terhadap berkurangnya kemantapan agregat.

Kasper et al. (2009) menyatakan sistem pengolahan intensif menurunkan kemantapan agregat makro (lebih dari $250 \mu \mathrm{m}$ ) dalam air yang dihubungkan dengan menurunnya bahan organik total tanah. Berdasarkan Indeks Dispersi Agregat yang ditunjukkan pada Tabel 4, perlakuan 50\% pupuk SP-36 + $50 \%$ MPF (Perlakuan D) mampu meningkatkan kestabilan agregat tanah Ultisol Jatinangor dengan nilai Indeks Dispersi Agregat sebesar 10 yang berpotensi dapat meningkatkan hasil terbaik. 
Tabel 2 Pengaruh kombinasi pupuk $\mathrm{P}$ dan MPF terhadap stabilitas agregat tanah pada Ultisols Jatinangor

\begin{tabular}{|c|c|c|}
\hline Perlakuan & $\begin{array}{c}\text { Indeks Dispersi } \\
\text { Agregat }\end{array}$ & $\begin{array}{c}\text { Kemantapan } \\
\text { Agregat* }\end{array}$ \\
\hline A & 14 & $\begin{array}{c}\text { Sangat Tidak } \\
\text { Mantap }\end{array}$ \\
\hline B & 13 & Tidak Mantap \\
\hline $\mathrm{C}$ & 12 & Tidak Mantap \\
\hline $\mathrm{D}$ & 10 & Tidak Mantap \\
\hline E & 11 & Tidak Mantap \\
\hline $\mathrm{F}$ & 11 & Tidak Mantap \\
\hline G & 12 & Tidak Mantap \\
\hline $\mathrm{H}$ & 11 & Tidak Mantap \\
\hline I & 11 & Tidak Mantap \\
\hline
\end{tabular}

*Kriteria menurut Balai Penelitian Tanah (2005)

Hasil tersebut lebih mantap dibandingkan dengan hasil analisis awal tanah yang menunjukkan nilai Indeks Dispersi Agregat tanah sebesar 15 dan perlakuan kontrol sebesar 14. Hal tersebut sesuai dengan pernyataan Jastrow et. al. (2007) bahwa dengan adanya JPF dapat mengikat butiran tanah dengan hifa jamur yang dapat memantapkan agregat tanah. Mikroorganisme menghasilkan senyawa ekspolisakarida yang akan merekatkan partikel tanah sehingga agregat tanah dapat terbentuk menjadi mantap dan stabil.

Menurut Balai Penelitian Tanah (2005) bahwa semakin rendah nilai Indeks Dispersi Agregat tanah maka stabilitas agregat tanah semakin mantap. Berdasarkan hal tersebut maka kombinasi pupuk SP-36 dan MPF mampu meningkatkan kestabilan agregat tanah. Pupuk SP-36 adalah pupuk P yang mudah tersedia bagi tanaman terlebih bila aplikasinya bersamaan dengan penggunaan pupuk organik maupun pupuk organik hayati. Hal ini membuktikan walaupun pupuk SP-36 merupakan pupuk $\mathrm{P}$ yang mudah tersedia namun tanpa aplikasi bersamaan dengan pupuk organik/organik hayati diduga SP-36 belum dapat memantapkan stabilitas agregat tanah secara optimal.

\subsection{Bobot Pipilan Kering Jagung}

Perlakuan kombinasi dosis pupuk $\mathrm{P}$ dan MPF berpengaruh nyata terhadap bobot pipilan kering jagung. Berdasarkan Tabel 3 tersebut, perlakuan yang diberikan keseluruhan berbeda nyata dengan kontrol, yang berarti perlakuan yang diberikan dapat memberikan pengaruh yang lebih baik terhadap hasil pipilan jagung.

Kombinasi dosis pada perlakuan 100\% pupuk P (SP-36) + 150\% pupuk MPF berhasil meningkatkan hasil panen berat pipilan kering sebesar $8,25 \mathrm{~kg} /$ plot atau 11,40 t/ha dengan peningkatan sebesar 20,67\% dibandingkan kontrol dengan hasil panen berat pipilan kering yaitu sebesar 7,74 $\mathrm{kg} /$ plot atau 10,69 $\mathrm{t} /$ ha dengan peningkatan $13,12 \%$.

Tabel 3 Pengaruh kombinasi pupuk $\mathrm{P}$ dan MPF terhadap bobot pipilan kering jagung

\begin{tabular}{cccc}
\hline \multirow{2}{*}{ Perlakuan } & \multicolumn{2}{c}{ Rata-rata } & Peningkatan \\
\cline { 2 - 3 } & (kg/plot) & $(\mathrm{t} / \mathrm{ha})$ & $(\%)$ \\
\hline A & 6,84 a & 9,45 & - \\
B & $7,39 *$ & 10,22 & $8,14 \%$ \\
C & $7,43 *$ & 10,27 & $8,73 \%$ \\
D & $7,40 *$ & 10,22 & $8,19 \%$ \\
E & $7,74 *$ & 10,69 & $13,12 \%$ \\
F & $7,38 *$ & 10,20 & $8,00 \%$ \\
G & $7,38 *$ & 10,21 & $8,00 \%$ \\
H & $7,43 *$ & 10,27 & $8,68 \%$ \\
I & $8,25 *$ & 11,40 & $20,67 \%$ \\
\hline
\end{tabular}

Keterangan: Nilai rata-rata pada kolom yang sama yang ditandai dengan huruf yang sama tidak berbeda nyata dengan kontrol menurut Uji Lanjut LSD pada taraf nyata $5 \%$.

Penelitian ini menunjukkan bahwa pada perlakuan $100 \%$ pupuk P $(\mathrm{SP}-36)+150 \%$ MPF memberikan peningkatan tertinggi terhadap hasil panen berat pipilan kering. Namun jika dilihat dari efisiensi input ke dalam tanah, perlakuan 50\% Pupuk SP-36 + $100 \%$ MPF (Perlakuan E) merupakan 
perlakuan yang dapat berpotensi lebih baik dengan hasil yang tidak berbeda nyata dibanding perlakuan tertinggi.

Pada fase generatif tanaman jagung membutuhkan unsur $P$ untuk pembentukan bunga dan buah. Pada tanaman serelia seperti jagung unsur $\mathrm{P}$ di simpan pada bulir-bulir jagung. Bulir-bulir jagung ini biasanya mengandung unsur $\mathrm{P}$ dalam bentuk polifosfat dengan kandungan mencapai 60-70\% polifosfat (Johnston, 2000). Pemberian pupuk $P$ pada pertanaman menyebabkan tersedianya $P$ bagi tanaman, Pemberian MPF pun dapat membantu meningkatkan $P$ yang dapat diserap tanaman. Unsur P berperan penting dalam fase generatif tanaman seperti pembentukan bunga dan buah (Hardjowigeno, 2010).

Pemberian dosis pupuk P (SP 36) yang tinggi atau sama dengan pupuk hayati pelarut fosfat tidak meningkatkan hasil panen berat pipilan kering, bahkan terjadi penurunan ratarata berat pipilan kering dibandingkan pemberian pupuk MPF yang lebih tinggi. Menurut Barus (2005) pemupukan P dengan takaran yang tinggi akan menyebabkan kahatnya unsur hara mikro seperti Zn, Fe, Bo, dan Mn sehingga unsur hara menjadi tidak seimbang dan akibatnya akan mengganggu aktivitas akar untuk menyerap unsur hara. Meningkatkan kecukupan salah satu hara yang tidak diikuti oleh meningkatnya kecukupan hara lainnya maka keseimbangan hara akan terganggu, menyebabkan pertumbuhan dan produksi menurun.

\section{KESIMPULAN}

Kombinasi dosis pupuk P (SP 36) dan pupuk hayati MPF berpengaruh nyata terhadap peningkatan populasi Jamur Pelarut Fosfat (JPF) dan hasil pada tanaman jagung pada Tanah Ultisol Jatinangor, namun tidak berpengaruh nyata terhadap stabilitas agregat tanah.
Kombinasi dosis 50 kg ha-1 pupuk SP $36+$ $50 \mathrm{~kg}$ ha-1 pupuk hayati MPF merupakan dosis terbaik dalam meningkatkan populasi JPF dan hasil tanaman jagung serta kombinasi dosis $50 \mathrm{~kg}$ ha-1 pupuk SP $36+25 \mathrm{~kg}$ ha- 1 pupuk hayati MPF memberikan peningkatan tertinggi terhadap stabilitas agregat tanah.

\section{UCAPAN TERIMA KASIH}

Terima kasih disampaikan kepada KEMENRISTEKDIKTI yang telah mendanai penelitian Strategis Nasional tahun anggaran 2016.

\section{DAFTAR PUSTAKA}

Balai Penelitian Tanah. 2005. Petunjuk Teknis Analisis Kimia Tanah, Tanaman, Air dan Pupuk. Balai Penelitian Tanah, Badan Penelitian dan Pengembangan Pertanian. Departemen Pertanian. Bogor.

Barus, J. 2005. Respon tanaman padi terhadap pemupukan $P$ pada tingkat status hara $\mathrm{P}$ tanah yang berbeda. Jurnal Akta Agrosia 8(2): 52-55.

Elfiati, D. dan Rauf, A. 2000. Uji pemanfaatan jamur pelarut fosfat untuk peningkatan efisiensi pemupukan $P$ pada Aeric Haplaquox. Prosidng Kongres Nasional VII HITI. Buku I. Hal. 645 - 654. Bandung, 2-4 November 1999.

Fitriatin, B.N., A. Yuniarti, O. Mulyani, F.S., Fauziah, M.D., Tiara. 2009. Pengaruh mikroorganisme pelarut fosfat dan pupuk $\mathrm{P}$ terhadap $\mathrm{P}$ tersedia, aktivitas fosfatase, populasi mikroorganisme pelarut fosfat, konsentrasi $\mathrm{P}$ tanaman dan hasil padi gogo (Oryza sativa, L.) pada Ultisols. Jurnal Agrikultura, 20 (3): 210-215.

Hardjowigeno S. 2010. Ilmu Tanah. Akademika Pressindo. Jakarta. 
Jastrow, J.D., J.E. Amonette and V.L. Bailey. 2007. Mechanisms controlling soil carbon turnover and their potential application for enchancing carbon sequestration. Climate Change 80(12):5-23.

Johnston, A. E. 2000. Soil and Plant Phosphate. International Fertilizer Industry Association. Paris.

Kasno, A, D. Setyorini dan E. Tuberkih. 2006. Pengaruh pemupukan fosfat terhadap produktivitas tanah Inceptisol dan Ultisol. Jurnal Ilmu-Ilmu Pertanian Indonesia 8 (2): 91 - 98.

Kasper M, GD Buchan, A Mentler, and WEH Blum. 2009. Influence of soil tillage system on aggregate stability and the distribution of $\mathrm{C}$ and $\mathrm{N}$ in different aggregate fractions. Soil and Tillage Research 105(2): 192-199.

Loveday, J. 1974. Methods for Analysis of Irrigted Soils Tech. Comm. No. 54 Commonwealth Agriculture Bureau, Ciro, Canberra.

Masni, E R., Bintang dan Purba M. 2015. Pengaruh interaksi bahan mineral dan bahan organik terhadap sifat kimia Ultisol dan produksi tanaman sawi. Jurnal Online Agroteknologi 3(4): $1489-1494$.

Parman, S. 2007. Pengaruh pemberian poupuk organik cair terhadap pertumbuhan dan produksi kentang (Solanum tuberosum L.). Buletin Anatomi dan Fisiologis 15(2): 21-31.

Prasetyo, B.H. dan Suriadikarta, D.A. 2006. Karakteristik, potensi, dan teknologi pengelolaan tanah Ultisol untuk pengembangan pertanian lahan kering di Indonesia. Jurnal Litbang Pertanian, 25(2): 39 - 46.

Simanungkalit, R.D.M., D.A., Suriadikarta, R. Saraswati, dan W. Hartatik. 2006.
Pupuk Organik dan Pupuk Hayati. Balai Besar Litbang Sumberdaya Lahan Pertanian. Badan Penelitian dan Pengembangan Pertanian. Bogor.

Sitorus, T.E. 2013. Analisis Status Hara Fosfor Pada Berbagai Lahan Pertanian Pangan di Pulau Jawa. Skripsi IPB. Bogor.

Suliasih, Widawati, S., Muharam, A. 2010. Aplikasi pupuk organik dan bakteri pelarut fosfat untuk meningkatkan pertumbuhan tanaman tomat dan aktivitas mikroba tanah. J. Hort. 20(3):241-246.

Sutoro. 2015. Determinan agronomis produktivitas jagung. Iptek Tanaman Pangan 10 (1): 39 - 46. 